\title{
QUANTUM LEARNING DAN FITRAH MANUSIA \\ DALAM PERSPEKTIF PENDIDIKAN ISLAM
}

\author{
Muhammad Miftah \\ Institut Agama Islam Negeri Kudus \\ Mochamad Nasichin Al Muiz \\ Institut Agama Islam Negeri Tulungagung
}

Abstract: Human nature in Islam does not mean "empty" without having any provision, but nature here is interpreted to bring talent or it is called as human potential. Each individual has unique potential and different from other individuals. This potential difference as one of the indigenous individual potentials of each individual, the potential here can be a strength as well as a weakness on the other side, just how individuals develop and optimize their potential. The Quantum learning model praxis combines uniqueness that arises from the individual so that it becomes a "symphony" cohesion that will unleash the full potential of the individual, without closing and ignoring the uniqueness and differences in the potential of the students. Through Sigmund Freud's psychoanalytic theory approach (id, ego, superego) found a common thread between the integration of individual potential in jumping up the potential possessed by individuals in the perspective of Islamic education. Human instincts want to get a comfort and happiness in various situations, in this case quatum learning can harmonize the three elements (id, ego, superego) that humans have in the learning process.

Keywords: quantum learning, human nature, psychoanalysis, islamic education.

Abstrak: Fitrah manusia dalam Islam bukan berarti "kosong" tanpa mempunyai bekal apa pun, melainkan fitrah di sini diartikan membawa bakat atau disebut dengan potensi insaniah. Masing-masing individu memiliki potensi unik dan berbeda dengan individu lain. Perbedaan potensi inilah sebagai salah satu potensi indigenos masing-masing individu, potensi di sini dapat menjadi kekuatan sekaligus kelemahan di sisi yang lain, tinggal bagaimana individu mengembangkan dan mengoptimalkan potensi yang dimilikinya. Model pembelajaran quantum learning secara praksis memadukan keunikan-keunikan yang muncul dari individu sehingga menjadi keterpaduan "simfoni" yang akan melejitkan seluruh potensi yang dimiliki individu, tanpa menutup dan mengabaikan keunikan dan perbedaan potensi yang dimiliki peserta didik. Melalui pendekatan teori psikoanalisa Sigmund Freud (id, ego, superego) ditemukan benang merah antara keterpaduan potensi individual dalam melejitkan potensi yang dimiliki individu dalam perspektif pendidikan Islam. Naluri manusia menginginkan akan kenyamanan dan kebahagiaan dalam pelbagai situasi, dalam hal ini quantum learning dapat menyelaraskan tiga unsur (id, ego, superego) yang dimilki manusia dalam proses pembelajaran.

Kata Kunci: Quantum Learning, fitrah manusia, psikoanalisis, pendidikan Islam. 


\section{A. PENDAHULUAN}

Pendidikan merupakan ornamen dalam membangun sendi-sendi kehidupan dalam segala aspek. Maka dari itu, pendidikan selalu mengikuti perkembangan serta kemajuan suatu peradaban, seperti halnya pendidikan yang ada di Indonesia selalu "mengekor" dengan pendidikan negara lain yang lebih maju, dengan harapan bangsa Indonesia dapat bersaing minimal dapat bersanding sejajar dengan negara-negara lain (Miftah, 2017: 234). Kesadaran ini pun didukung dengan berbagai upaya, baik yang dilakukan pemerintah melalui pelbagai program kebijakan yang selama ini membelenggu proses pembelajaran. Salah satu upaya pemerintah dalam mengupayakan pembelajaran yang humanis ialah dikeluarkannya kebijakan Merdeka Belajar di awal-awal kepemimpinan Nadiem Makarim, membuka kran pembelajaran yang selama ini kaku, statis dan kurang memberi ruang ekspresi guru untuk mengembangkan potensi yang dimilikinya karena terkungkung akan aturan yang bersifat birokratis yang menghambat akan keberhasilan proses pembelajaran.

Keberhasilan proses pembelajaran ialah dapat memanfaatkan media dan mengoptimalkan potensi dan daya yang ada. Optimalisasi potensi dan daya, dalam hal ini pemakalah mengistilahkan dengan 'quantum'. Istilah quantum, secara historis awalawalnya hanya digunakan oleh pakar fisika modern menjelang abad 20, kemudian berkembang secara luas merambat ke bidang-bidang kehidupan manusia lainnya. Quantum berarti segala interaksi yang muncul yang mampu mengubah energi menjadi cahaya. Quantum learning, dapat diartikan orkestrasi bermacam-macam interaksi yang ada di dalam dan di sekitar proses pembelajaran. Proses interaksi ini mencakup unsurunsur untuk belajar efektif dan mengubah kemampuan bakat alamiah siswa menjadi cahaya yang bermanfaat bagi individunya dan orang lain (DePorter et al., 1999: 6). Namun, realitas saat ini, fenomena generasi $\mathrm{Z}$ dalam proses pembelajaran sering menafikkan dimensi sosial yang ada di sekitarnya, mereka lebih memilih kenyamanan individu dan acuh dengan apa yang terjadi disekitarnya (Saragih, 2012, p. 12). Maka perlu menyelaraskan dan menyeimbangkan potensi dan daya ini sebagai salah satu kunci keberhasilan proses pembelajaran. Keselarasan dan keseimbangan di sini mengarah pada titik keseimbangan equality manusia dalam mengoptimalkan potensi dan daya yang dimilikinya.

Dalam upaya mengembangkan potensi dan daya yang dimiliki individu, individu (manusia pembelajar) membutuhkan adanya bantuan individu lain (lingkungan sosial) untuk membimbing, mendorong, dan mengarahkan agar pelbagai potensi tersebut dapat bertumbuh dan berkembang secara wajar dan optimal, sehingga kelak hidupnya dapat berdaya guna dan berhasil guna. Dengan begitu, mereka akan dapat memenuhi kebutuhan hidupnya dan dapat menyesuaikan diri dengan lingkungannya (Zuhairini, 1995: 96). Hal ini selaras dengan prinsip dalam pembelajaran quantum learning memiliki falsafah dasar tentang eksistensi manusia yaitu potensi natural yang dimiliki setiap manusia yang dapat berkembang sesuai rangsangan dan keadaan lingkungan (DePorter \& Hernacki, 1999: 9). Lingkungan yang dapat membentuk dan mengoptimalkan potensi, lingkungan yang mempengaruhi di sini dapat dilihat dari lingkungan sekolah, lingkungan keluarga, masyarakat ataupun lingkungan sosial yang ada di sekitar tumbuh kembang peserta didik di sini diartikan sebagai faktor eksternal yang mempengaruhi secara langsung proses pembelajaran yang sedang dilakukan.

Proses pembelajaran tidak hanya sebatas interaksi seorang pendidik dengan peserta didik, melainkan lebih dari itu yaitu menata latar pembelajaran, media, dan lingkungan pembelajaran (Djihad, 2012: 49). Memang sangat kompleks untuk mengarah pada suatu proses pembelajaran yang "ideal". Perlu diperhatikan juga tentang ketersediaan media, sarana dan prasarana, kompetensi pendidik, dan tidak kalah penting yaitu ketepatan memilih strategi (metode) pembelajaran menjadi hal yang urgen dalam 
kesuksesan proses pembelajaran. Maka ada adagium yang cukup masyhur mengenai perihal metode ini yaitu "At-Thariqatu ahammu min al-maadah wa mudarrisu ahammu min at-thariqah wa ruuhul mudariris ahammu min kulli syain". Metode memang mempunyai peran sentral dalam proses pembelajaran, akan tetapi yang lebih penting dari itu bagaimana kualitas (spiritual dan kognitif) pendidik itu sendiri dalam mengajar menempati bagian terpenting dalam pembelajaran.

Model pembelajaran quantum learning dalam riset yang dilakukan Kukuh Andri Aka terbukti sangat efektif dilakukan dalam pelbagai jenjang pendidikan terutama dalam jenjang pendidikan dasar (Aka, 2016: 35-40). Riset ini mencoba menerapkan model pembelajaran quantum learning dalam pembelajaran PKn di Sekolah Dasar dalam tiga siklus pembelajaran, dari siklus satu sampai dengan siklus ke tiga terjadi perubahan signifikan kemampuan afektif, kognitif, dan psikomotorik siswa terlihat dari hasil pembelajaran dan pengamatan yang dilakukan.

Ciri utama kegiatan pembelajaran adalah adanya interaksi. Interaksi yang terjadi antara siswa dengan lingkungan belajarnya, baik dengan guru, teman- temannya, tutor, media pembelajaran, dan sumber-sumber belajar lainnya (Junaidah, 2015: 114). Model interaksi dalam proses pemebalajaran yang dilakukan dan dipilih oleh seorang guru dengan seorang siswa disinilah disebut dengan metode pembelajaran. Tidak ada metode pembelejaran yang paling baik dibandingkan dengan metode pembelajaran yang lainnya, setiap metode pembelajaran memiliki kekurangan dan kelebihan disetiap situasi dan kondisi dalam pembelajaran.

Pendekatan quantum learning, dianggap salah satu pendekatan yang paling relevan dalam upaya optimalisasi potensi atau kemampuan dasar yang dimiliki oleh manusia. Pemanfaatan potensi yang dimiliki manusia tersebut dilakukan dengan berbagai macam cara atau tehnik yang melibatkan keseluruhan kepribadian baik intelek, fisik maupun emosi (Zayadi, 2017: 6). Maka dalam artikel ini penulis mencoba mengelaborasi pendekatan quantum learning dengan lingkungan belajar, metode pembelajaran dan fitrah manusia sebagai mahluk Allah yang memiliki potensi yang sangat beragam dilihat dari perspektif pendidikan Islam.

\section{B. METODE}

Dalam penelitian ini peneliti menggunakan metode penelitian kualitatif dengan pendekatan kepustakaan (library research) dalam mengaitkan antara quantum learning dengan fitrah manusia dan dikaji dalam perspektif pendidikan Islam. Peneliti menghimpun berbagai informasi baik berupa hasil penelitian, buku, ensiklopedi dan karya ilmiah yang relevan dengan topik yang sedang diteliti. Dalam penelitian kepustakaan setidaknya terdapat dua sumber yang dapat dijadikan rujukan dalam penelitian (Harahap, 1995: 45). Pertama, sumber yang sifatnya primer, peneliti menggunakan buku-buku terkait pembelajaran quantum learning dalam pendidikan dan psikologi pendidikan Islam. Kedua, sumber yang sifatnya sekunder yaitu artikel atau referensi buku yang membahas mengenai strategi pembelajaran dalam pendidikan agama Islam.

Sedangkan dalam analisis data dalam penelitian kepustakaan menurut (Kaelan, 2010: 135) terdapat dua tahap dalam menganilisis data penelitian kepustakaan; Pertama, proses analisis dimulai ketika mengumpulkan data dari berbagai sumber. Kedua, analisis data ketika selesai pengumpulan data baru dianalisis, selanjutnya data yang didapatkan terkait dengan fitrah manusia dan pembelajaran quantum learning dikomparasikan dan dianalisis menggunakan pendekatan dalam perspektif pendidikan agama Islam. 


\section{URGENSI QUANTUM LEARNING YANG HUMANIS DAN KONSTRUKTIVIS}

Quantum learning merupakan seperangkat metode dan falsafah belajar yang terbukti efektif di sekolah dan bisnis untuk semua tipe orang dan segala usia. Quantum learning pertama kali digunakan di Supercamp. Di Supercamp ini menggabungkan rasa percaya diri, keterampilan belajar, dan keterampilan berkomunikasi dalam lingkungan yang menyenangkan.(DePorter, 2010) Suggestology atau sugges-to-pedia menjadi prinsip mendasar bagi pembelajaran quantum learning, setiap sugesti yang diberikan kepada individu dapat mempengaruhi hasil studi belajar (DePorter \& Hernacki, 1992).

Pengajaran sugestif diperlukan sebagai keterampilan memunculkan kreativitas memberikan sugesti positif kepada peserta didik. Sugesti positif di sini sebagai upaya untuk mempengaruhi hasil belajar, dengan tehnik memberikan memposisikan peserta didik dengan nyaman, mengatur suasana pembelajaran dengan sedemikian rupa, memasang musik latar di dalam kelas, menggunakan poster-poster untuk memberi kesan besar sambil memberikan informasi dalam poster tersebut. Dalam terminologi lain suggestology dapat diartikan juga dengan accelerated learning (percepatan belajar), percepatan belajar bukan berarti memaksakan siswa untuk mendapatkan materi secara instan, akan tetapi konsep pembelajaran yang mengesankan dengan diiringi kegembiraan. Konsep ini memang sekilas tidak mempunyai sisi kesamaan, namun unsur-unsur dalam proses pembelajaran yang menyenangkan dapat menghasilkan pengalaman pembelajaran yang efektif dan menyenangkan.

Pembelajaran quantum learning mencakup aspek-aspek penting dalam neurolinguistik (NLP). Para pendidik dengan pengetahuan NLP dapat memilah dan memilih bahasa positif dalam proses pembelajaran, sebagai upaya merangsang fungsi otak yang paling efektif. Hal ini juga dapat memunculkan gaya belajar terbaik dari setiap orang dan menciptakan "pegangan" dari saat-saat keberhasilan yang meyakinkan (DePorter \& Hernacki, 1999: 14). Perangsangan otak melalui pemilihan bahasa yang tepat (Sugesti) disini berdampak signifikan terhadap style belajar siswa yang menggugah potensi yang dimiliki peserta didik.

Potensi yang dimaksud dalam pendidikan Islam diartikan sebagai fitrah (bawaan lahir) yang lebih diarahkan ada potensi untuk "beragama", sedangkan dalam proses pembelajaran quantum learning lebih diarahkan pada kemampuan yang dimiliki manusia untuk berkembang berdasarkan aspek fisiologis yang dimilikinya (Zayadi, 2017: 130). Quantum learning secara jelas menafikkan akan pandangan empirisme John Locke tentang teori tabula rasa yang beranggapan manusia dilahirkan dalam keadaan kosong, tidak membawa apapun kecuali raga yang sifatnya "fisikly" dan tidak mempunyai daya apapun (Tafsir, 1992: 137).

Sebagai penguat quantum learning dalam praktik pembelajarannya selalu memperhatikan lingkungan di luar individu sebagai "panggung pentas" yang mendorong dan mempengaruhi proses pembelajaran, mulai dari penataan musik, suasana kelas, penataan cahaya dan lain sebagainya dapat menciptakan lingkungan yang optimal, baik secara fisik maupun mental peserta didik. Lebih detailnya dapat dilihat dalam gambar di bawah ini: 


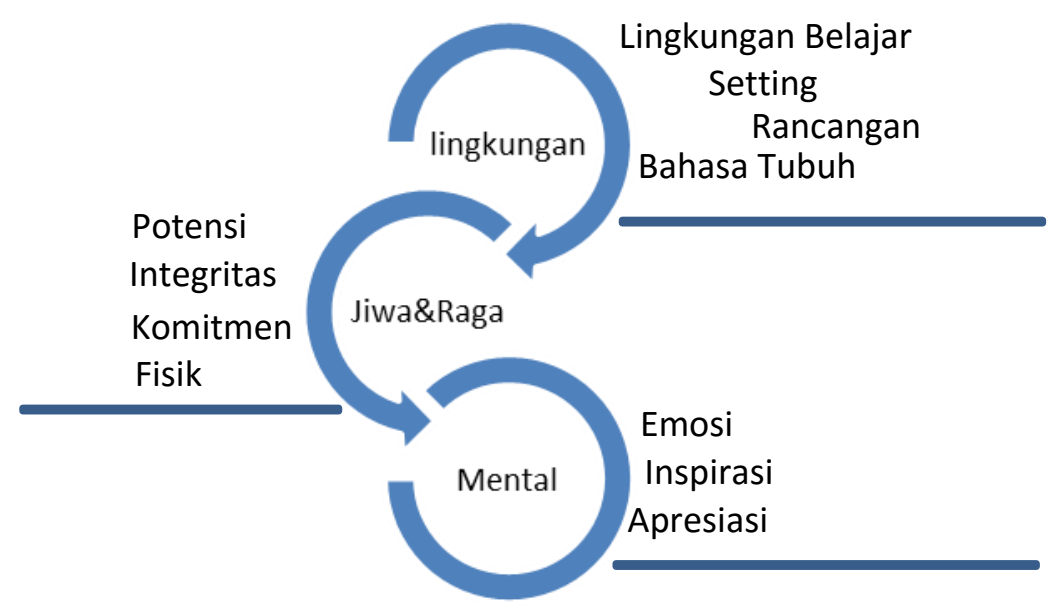

Integrasi keterampilan akademis, prestasi fisik, dan keterampilan dalam merupakan inti dari pembelajaran quantum learning. Yang mendasari falsafah ini yaitu "kami yakin agar efektif belajar adalah dapat dan harus menyenangkan, belajar adalah kegiatan seumur hidup yang dapat dilakukan dengan menyenangkan dan berhasil, seluruh pribadi adalah penting akal, fisik dan emosi/pribadi, bahwa kehormatan diri adalah material yang penting dalam membentuk pelajar yang sehat dan bahagia" (Riyanto, 2009: 183). Sebagai konsekuensi dari falsafah ini lingkungan harus dikemas sedemikian mungkin agar peserta didik merasa nyaman dan aman dengan mengharmonisasikan lingkungan fisik, dengan lingkungan emosi peserta didik. Lingkungan emosi peserta didik di sini dimaksudkan dalam program pembimbingan dan membentuk jalinan pengertian setelah peserta didik menetapkan pilihan bidang studi dan menghadapkan pada tantangan mereka dalam memperoleh kesuksesan. Quantum learning merupakan menggabungkan suggestology, teknik percepatan belajar, dan NLP dengan teori keyakinan, termasuk diantaranya konsep-konsep kunci dari berbagai teori dan strategi belajar yang lain seperti: Teori otak kanan dan kiri, pilihan modalitas (visual, auditorial, dan kinestik), teori kecerdasan ganda, pendidikan holistik, belajar berdasarkan pengalaman, belajar dengan simbol dan simulasi permainan (Riyanto, 2009: 185).

\section{QUANTUM LEARNING, PSIKOANALISA, DAN FITRAH MANUSIA DALAM DISKURSUS PENDIDIKAN ISLAM}

Kesuksesan dalam proses pembelajaran sangat dipengaruhi dua faktor yang selalu berkelindan dan tidak bisa dipisahkan dalam interaksi pembelajaran di kelas maupun luar kelas. Faktor yang muncul dari diri siswa internal, faktor yang muncul dari luar diri siswa eksternal (Wahidi, 2017: 100). Faktor internal siswa seperti bakat, semangat, kreativitas, etos belajar dan potensi yang dimilikinya sejak ia dilahirkan di dunia pendidikan Islam hal ini disebut dengan dengan "fitrah" (potensi) yang sejak lahir manusia membawa fitrah masing-masing. Sedangkan faktor eksternal di sini yang muncul dari luar diri siswa yang mampu merangsang dan mengembangkan potensi yang dimiliki siswa (individu), bisa berupa suasana kelas, iklim belajar, maupun iklim cuaca, strategi pembelajaran, sarana dan prasarana, termasuk juga di sini produk kebijakan pembelajaran.

Asril dalam artikelnya dengan judul Fitrah Manusia dan Pendidikan Islam dalam perspektif filsafat pendidikan Islam mengatakan, "Aktivitas pendidikan berkaitan erat dengan proses pemanusiaan manusia (humanizing of human being) atau upaya untuk membantu subjek (individu) secara normatif berkembang lebih baik (Asril, 2018: 220). Sedangkan tugas pendidikan yaitu memastikan bagaimana kebutuhan dan hak manusia 
hidup itu dapat terwujud tanpa ada pengecualian (Arifin, 1994: 65). Di antara masalah terpenting yang harus diperhatikan ialah mengetahui bakat dan pekerjaan yang sesuai dengan anak, yang menjadi cita-cita hidupnya. Diantara anak-anak terdapat kesenjangan dalam hal kecerdasan dan kemampuan (Mualimin, 2017: 265).

Interaksi dalam proses pembelajaran seharusnya memosisikan siswa sebagai manusia seutuhnya, dengan mempertimbangkan segala potensi yang dimilikinya. Potensi-potensi yang belum muncul seharusnya digali dan dikembangkan inilah kesulitan seorang guru ketika mendiagnosis potensi yang dimiliki siswa dan memapu mengoptimalkan potensi yang ada dengan strategi pembelajaran yang sesuai dengan karakteristik siswa.

Konsep fitrah tidaklah identik dengan teori tabula rasa, begitu juga perspektif Islam terhadap manusia tidaklah identik dengan aliran dualisme maupun konvergensi, sebab teori tabula rasa sebagaimana yang dikemukakan John Locke, berpandangan bahwa manusia seperti kertas putih bersih yang belum terkena tepaan tinta (Assegaf, 2014: 47). Teori tabula rasa menganggap keberadaan manusia dengan keadaan hampa (pasif), melainkan fitrah dalam hal ini lebih mengarah kepada fitrah dengan membawa potensi dan daya yang bisa dikembangkan, tinggal lingkungan dan pendidikannya seperti apa membentuk dan mengarahkannya.

Dengan demikian, konsep fitrah dalam hal ini memberi keseimbangan (equality) dengan teori-teori yang lain. Teori bad active, misalnya memandang bahwa manusia terlahir dengan membawa potensi kejelekan atau kejahatan. Maka disini peran lingkungan dan pendidikanlah bertugas untuk meluruskan potensi jahat tersebut. Selain itu ada teori good active berpandangan bahwa semua manusia lahir dengan membawa potensi kebaikan, lingkungan dan pendidikanlah yang mengubah potensi baik tersebut bisa semakin baik atau bahkan sebaliknya. Maka muncul teori yang mencoba memadukan antara dua teori besar ini, dikenal dengan Teori Neutral-active, teori ini setidaknya mempercayai kedua akan teori potensi manusia yang di atas dalam bentuk konvergensi (Assegaf, 2014: 49).

Fitrah manusia perspektif Ibnu Sina, membahasakan dengan istilah jiwa (insaniah) yang disebut juga dengan al-nafs al-nathiqat, mempunyai dua daya yaitu; Pertama, daya praktis (al-amilah) hubungannya dengan jasad. Kedua, Daya teoretis (alalimah) hubungannya dengan hal-hal yang bersifat abstrak. Daya jiwa al-alimah disebut juga aql al-nazhari (akal intelegensia teoritis), daya jiwa ini menemukan konsep-konsep yang bersifat umum yang ditimbulkan oleh materi. Daya teoretis ini memiliki beberapa tingkatan akal, yaitu: a) al-aql bi al quwaab, yaitu intelegensia yang berkembang berdasarkan interaksi dan hubungan dengan dunia luar (baca: lingkungan) melalui belajar atau dengan pengalaman-pengalaman yang lainnya. Di dalamnya terdapat; 1) alaql al-hayulani (akal material), al-aql al-malakat (kebenaran aksioma). 2) al-aql almustafad (konsepsi rasional). Pandangan Ibnu Sina tentang daya inilah yang dilihat dapat berhubungan dan menerima limpahan ilmu pengetahuan dari akal aktif (Muhammad Iqbal, 2015: 5-7). Sebagai upaya peningkatan akal dan kualitas jiwa manusia Ibnu Sina, menegaskan pentingnya pendidikan dan lingkungan pendidikan yang dapat mendorong optimalisasi daya (kecerdasan) yang dimiliki manusia.

Diskursus makna kecerdasan sangatlah luas. Teori kecerdasan terus berkembang, mulai dari Plato, Aristoteles, Darwin, Alferd Binet, Stanberg, Piaget, sampai Howard Gardner, dari dinamika perkembangan yang pesat ini mengerucut pada pola yang sama, yaitu makna kecerdasan banyak ditentukan oleh faktor situasi dan kondisi (konteks). Kecerdasan bagi Gardner bersifat dinamis (berkembang), maka kecerdasan seseorang dapat dilihat dari pola tingkah laku seseorang dalam kehidupannya dan bagaimana lingkungan membentuk serta mengoptimalkan potensi yang dimilikinya. 
Sedangkan kondisi sosial peserta didik menurut teori ekologi Urie sangat mempengaruhi perkembangan kecerdasan sosialnya, setidaknya ada lima sistem sosial yang saling memberikan pengaruh kepada interpersonal sampai ke kultur yang lebih luas (Santrock, 2007: 54). Lima sistem sosial di sini menurut pandangan Santrock yaitu: Microsystem (Setting/lokasi dimana individu menghabiskan waktunya yang dapat dipertimbangkan bersama keluarga, sekolah tetangga, kelompok keagamaan), Mesosyistem (hubungan diantara microsyistem, hubungan antara pengalaman dalam keluarga dan dalam sekolah), Exosystem (Pengalaman-pengalaman dalam setting sosial, dimana individu tidak memiliki peran aktif namun mempengaruhi apa yang individu alami), Macrosystem (Melibatkan budaya yang lebih luas, pengertian budaya di sini termasuk peran sosial dan sosio economi terhadap perkembangan individu), Chronosystem (Kondisi-kondisi sosio historikal dari perkembangan pelajar, sebagai contoh gaya hidup anak-anak sekarang sangat berbeda jauh dengan gaya hidup anakanak zaman dahulu). Teori ini menunjukkan bagaimana konteks pada kehidupan anak saling berkaitan dalam aplikasi penerapan pendidikan di sini perlu dipahami lima sistem dengan tujuan memaksimalkan peran pendidikan dalam membentuk perilaku sosial siswa maupun dalam mendidik siswa.

Pendidikan dipandang merupakan kegiatan manusia untuk memanusiakan dirinya sendiri, yaitu manusia berbudaya. Konstruktivis sebagai salah satu konsep yang banyak membicarakan masalah pembelajaran, diharapkan dapat menjadi landasan intelektual untuk menyusun dan menganalisis problem pembelajaran dalam pergulatan dunia pendidikan (Riyanto, 2009: 143). Dalam konteks filsafat pendidikan, konstruktivisme merupakan suatu aliran yang membangun tata susunan kehidupan membentuk kebudayaan yang bercorak kekinian (modern). Konstruktivis berupaya membina suatu konsensus yang paling luas dan mengenai tujuan pokok dan tertinggi dalam kehidupan umat manusia (Abdullah, 1997: 76).

Teori konflik kepribadiannya Freud, dalam proses penanaman nilai-nilai sosial, agama, budaya dalam pembelajaran sebagai media penanaman nilai-nilai moralitas (Super Ego) dari komunitas sosial yang lebih besar seperti keluarga, masyarakat, negara dan agama tetap penting keberadaannya. Karena hal ini berkaitan dengan keseimbangan dalam kepribadian manusia itu sendiri (Sumadi, 2018: 29). Dalam konteks bertujuan untuk mencerdaskan kehidupan bangsa dan mewujudkan manusia seutuhnya, pendidikan moralitas harus berjalan antara kognitif dan rekognitif tanpa ada reduksi diantara satu sama lain, karena manusia pada dasarnya memiliki dua sistem kehidupan. Yaitu kehidupan rohani dan jasmani. Kedua-duanya bersifat simbiosis atau organik satu sama lain dan harus menyatu serta berdampingan (Hariyanto, 2016: 105).

Pendidikan tidak sebatas pewarisan nilai-nilai budaya berupa kecerdasan dan keterampilan dari generasi tua kepada generasi muda, melainkan pendidikan berarti sebagai pengembangan potensi-potensi individu untuk kegunaan individu itu sendiri dan selanjutnya untuk kebahagiaan masyarakat (Langgulung, 1995: 261). Pengembangan potensi di sini searah dengan prinsip pembelajaran quantum learning yaitu menyelaraskan akan jiwa, lingkungan dan metal yang dimiliki peserta didik dalam "arena" pembelajaran, yang tujuan akhir dari proses pembelajaran ini adanya keseimbangan potensi diri yang dimiliki manusia melalui interaksi yang terwujud dalam sistem pembelajaran maupun dalam sosial kehidupan peserta didik.

\section{E. SIMPULAN}

Pembelajaran quantum learning memiliki falsafah dasar tentang eksistensi manusia yaitu potensi natural yang dimiliki setiap manusia yang dapat berkembang sesuai rangsangan dan keadaan lingkungan. Lingkungan yang dapat membentuk dan 
mengoptimalkan potensi, disini diartikan sebagai faktor eksternal yang mempengaruhi secara langsung proses pembelajaran yang sedang dilakukan.

Quantum learning secara jelas menafikkan akan pandangan empirisme John Locke tentang teori tabula rasa yang beranggapan manusia dilahirkan dalam keadaan kosong, seperti halnya kertas putih yang kosong, tidak membawa apapun kecuali raga yang sifatnya "fisikly" dan tidak mempunyai daya apapun. Sebagai penguat quantum learning dalam praktik pembelajarannya selalu memperhatikan lingkungan di luar individu sebagai "panggung pentas" yang mendorong dan mempengaruhi proses pembelajaran, mulai dari penataan musik, suasana kelas, penataan cahaya, dan lain sebagainya dapat menciptakan lingkungan yang optimal, baik secara fisik maupun mental peserta didik.

Pembelajaran quantum learning mengapresiasi akan peran potensi yang dimiliki masing-masing individu. Prinsip quantum learning ialah memandang manusia (peserta didik) secara holistik, akal-jiwa-fisik, maka model ini seirama dengan teori psikoanalisis yang dimilki Sigmund Freud harus ada keterpaduan antara (Id, Ego, Superego) sehingga dalam pengembangan potensi yang dimiliki manusia tidak menafikkan sifat lahiriah maupun batiniah yang dimiliki manusia. Dalam quantum learning menganggap bahwa pengembangan potensi disini dapat dilakukan dengan mengintegrasikan pelbagai elemen-elemen yang ada di dalam maupun di luar peserta didik. Dengan menyinergikan lingkungan-jiwa-fisik akan memunculkan pembelajaran yang humanis dan menyenangkan.

\section{Daftar Pustaka}

Aka, K. A. 2016. Model Quantum Teaching dengan Pendekatan Cooperative Learning untuk Meningkatkan Kualitas Pembelajaran PKn. Pedagogia: Jurnal Pendidikan, 5(1), 35-46.

Arifin, H. M. 1994. Filsafat Pendidikan Islam. Bumi Aksara.

Asril, A. 2018. Fitrah Manusia dan Pendidikan Islam (Perspektif Filsafat Pendidikan Islam). At-Ta'lim: Media Informasi Pendidikan Islam, 16(2), 215-234. https://doi.org/10.29300/attalim.v16i2.835

Assegaf, A. 2014. Filsafat Pendidikan Islam Paradigma Baru Pendidikan Hadhari Berbasis Integratif-Interkonektif. Raja Grafindo Persada.

DePorter, B. 2010. Mempraktikkan Quantum Learning di Ruang-ruang Kelas. Kaifa.

DePorter, B., \& Hernacki, M. 1992. Quantum Learning: Unleashing the Genius In You. Dell Publishing.

DePorter, B., \& Hernacki, M. 1999. Quantum Learning: Membiasaka Belajar Nyaman dan Menyenangkan. Kaifa.

DePorter, B., Reardon, M., \& Singger Nourie, S. 1999. Quantum Teaching: Orchestrating Student Success. Allyn and Bacon.

Harahap, S. 1995. Metodologi Studi dalam Penelitian Ilmu-Ilmu Ushuludin. Rajawali Pres. 
Hariyanto, I. 2016. Etika Psikoanalisis Sigmund Freud sebagai Landasan Kesalehan Sosial. Al-Tazkiah: Jurnal Bimbingan Dan Konseling Islam, 5(2), 97-107. https://doi.org/10.20414/altazkiah.v5i2.1185

Jalaluddin, \& Abdullah, I. 1997. Filsafat Pendidikan. Gaya Media Pratama.

Kaelan. 2010. Metode Penelitian Agama Kualitatif Interdisipliner. Paradigma.

Langgulung, H. 1995. Manusia dan Pendidikan Suatu Analisa Psikologi dan Pendidikan. Mutiara Sumber Widya.

Miftah, M. 2017. Model Integrasi Sains dan Agama dalam Pendidikan Nasional. Jurnal Penelitian, 233-246. https://doi.org/10.28918/jupe.v14i2.1214

Muhammad Iqbal, A. 2015. Pemikiran Pendidikan Islam. Pustaka Pelajar.

Riyanto, Y. 2009. Paradigma Pembelajaran Sebagai Referensi Bagi Pendidik dalam Implementasi Pembelajaran yang Berkualitas. Kencana Prenada Media Group.

Santrock. 2007. Psikologi Pendidikan, Edisi Kedua. Kencana Prenada Media Group.

Saragih, J. F. B. 2012. Fenomena Bermain Generasi Z dan Hubungannya dengan Eksistensi Ruang Bermain Terbuka di Lingkungan Perumahan Sederhana. ComTech, 3(1), 8-14.

Sumadi, E. 2018. Anomali Pendidikan Karakter. Tarbawi : Jurnal Pendidikan Islam, 15(2). https://doi.org/10.34001/tarbawi.v15i2.846

Suyanto, \& Djihad, A. 2012. Calon Guru dan Guru Profesional. Multi Presindo.

Tafsir, A. 1992. Filsafat Umum: Akal dan Hati Sejak Thales Sampai James. Remaja Rosda Karya.

Wahidi, A. 2017. Learning Quantum Chemical Model with Learning Media Concept Map and Power Point Viewed from Memory and Creativity Skills Students. JETL (Journal of Education, Teaching and Learning), 2(1), 100-104. https://doi.org/10.26737/jetl.v2i1.136

Zayadi, A. 2017. Quantum Learning Dalam Perspektif Pendidikan Islam. HIKMAH: Jurnal Pendidikan Islam, XIII(1).

Zuhairini. 1995. Filsafat Pendidikan Islam. Bumi Aksara. 